\title{
Primate Biliary Physiology VIII
}

\author{
THE EFFECT OF PHENOBARBITAL UPON BILE SALT \\ SYNTHESIS AND POOL SIZE, BILIARY LIPID SECRETION, \\ AND BILE COMPOSITION
}

\author{
Richard N. Redinger and Donald M. SMall \\ From the Department of Medicine, Boston University School of Medicine, \\ Boston, Massachusetts 02118
}

\begin{abstract}
A B S T R A T Phenobarbital, by inducing liver microsomal enzymes, may affect bile acid synthesis from cholesterol and thus alter the secretion of biliary lipids and the composition of bile. We, therefore, determined the effects of phenobarbital on bile flow, biliary lipid secretion, bile acid synthesis, and bile-acid pool size. Using an experimental preparation that allows controlled interruption of the enterohepatic circulation (1), we administered $5 \mathrm{mg} / \mathrm{kg}$ per day of phenobarbital to healthy Rhesus monkeys for 1-2 wk to achieve steady-state conditions. Three animals were studied with an intact enterohepatic circulation and three with a total bile fistula, each animal served as its own control. Total bile flow and secretion of bile salt, phospholipid, and cholesterol were measured every $24 \mathrm{~h}$ during steady-state conditions. Further, under conditions of an intact enterohepatic circulation bile-acid synthetic rate was measured in three animals and pool size estimated in two animals during both control and drug treatment periods.
\end{abstract}

Phenobarbital at doses of $5 \mathrm{mg} / \mathrm{kg}$ per day increased bile flow $30-50 \%$ in all animals $(P<0.001)$. The increased bile flow resulted from both an increased "bilesalt independent fraction" and an increased bile-salt secretion rate. Phenobarbital significantly increased bile salt $(P<0.01)$ and phospholipid secretion $(P<0.05)$

This work was presented in part at the joint session of The American Federation of Clinical Research and The American Society of Clinical Investigation, 2 May 1971. (Redinger, R. N., and D. M. Small. 1971. J. Clin. Invest. 50 : 76a. (Abstr.)

Dr. Redinger was an Ontario Department of Health Fellow. His present address is Department of Medicine, University of Western Ontario, London, Ontario, Canada.

Received for publication 28 February 1972 and in revised form 12 September 1972. by about $30 \%$ but cholesterol secretion was not significantly changed. Consequently, the concentration of cholesterol relative to bile salt and phospholipid was decreased $(P<0.001)$. Phenobarbital significantly enhanced the maximal rate of bile acid synthesis $25-30 \%$ in all three monkeys with total bile fistulas $(P<0.05)$ and also augmented bile acid synthesis and pool size in animals with intact enterohepatic circulations despite the fact that the rates of bile salt returning to the liver in these animals would have inhibited bile acid synthesis in control animals. Thus, phenobarbital not only increases the maximal rate of bile acid synthesis but also alters the normal control mechanisms by which bile salts returning to the liver inhibit bile salt synthesis. The fact that phenobarbital treatment results in increased synthesis of bile salt and unchanged secretion of cholesterol is consistant with the view that the drug augments conversion of hepatic cholesterol to bile salt. The resulting decrease in relative cholesterol content in bile may have therapeutic implications for cholesterol gallstone therapy.

\section{INTRODUCTION}

The enterohepatic circulation $(\mathrm{EHC})^{1}$ of bile salts begins with the synthesis of bile acids from cholesterol within the liver. Bile acids are then conjugated with glycine or taurine, secreted by the liver as bile salts into bile, and ultimately pass into the upper intestine. They then move down the small intestine and are absorbed partly from the upper small bowel by passive diffusion and from the ileum by a combination of active and pas-

${ }^{1}$ Abbreviation used in this paper: EHC, enterohepatic circulation. 
sive processes. After passing through the intestinal mucosal cells they return to the liver via the portal vein to complete the EHC. Normally, only a small amount of bile salt escapes absorption and is lost in feces. Thus, in a steady state, the body needs only to synthesize that amount of bile salt lost to maintain a constant bile-salt secretion rate and pool size (1).

In animals with a total bile fistula, bile acid synthesis is enhanced $(1,2)$. Furthermore, it has been demonstrated in the Rhesus monkey that bile acid synthesis in animals with an intact EHC (normal state) is low but increases in proportion to bile salt loss produced by a partial bile fistula (1). Thus, bile salt secretion (total quantity of bile salt leaving the liver per $24 \mathrm{~h}$ ) and bile salt pool are maintained in the face of increased bile salt loss up to a certain point by a compensatory increase in bile salt synthesis. Although bile acid synthesis can, in fact, increase about 10 -fold in response to bile salt loss, it cannot compensate adequately when the loss is great. Thus, when one-third or more of total bile salt secretion is diverted from the animal, bile acid synthesis, although maximal, cannot make up for loss and consequently both total bile salt secretion and pool are decreased (7). Shefer, Hauser, Bekersky, and Mosbach (3) have recently shown that the rate-limiting step in the synthesis of bile acid from cholesterol is the conversion of cholesterol to $7 \alpha$-hydroxycholesterol by the microsomal enzyme cholesterol $7 \alpha$-hydroxylase. Furthermore, $7 \alpha$-hydroxylation is normally significantly suppressed by feedback inhibition of bile salt returned to the liver via the portal vein (4).

Phenobarbital, a well-known microsomal enzyme inducer (5), can affect bile acid synthesis from cholesterol by altering the activity of the enzyme cholesterol $7 \alpha$-hydroxylase (6). It is also known that hepatic phospholipid content and synthesis are increased in proliferating endoplasmic reticulum of rats pretreated with phenobarbital $(7,8)$. If the hepatic metabolism of bile salt, phospholipid, and cholesterol were altered by phenobarbital then the secretion of these lipids might also be altered. If the secretion rate of any lipid is altered out of proportion to that of the other lipids, the composition of bile relative to bile salt, phospholipid, and cholesterol would also be changed. It is, therefore, possible that phenobarbital treatment increases bile salt synthesis from cholesterol and causes increased bile salt and decreased cholesterol secretion. Furthermore, if the increased phospholipid synthesis also resulted in increased phospholipid secretion then the bile secreted by phenobarbital-treated animals ought to have significantly more bile salt and phospholipid but less cholesterol. Since this hypothesis cannot easily be tested in man, we utilized a chronic monkey model developed in our laboratory $(9,10)$ to study the effects of phenobarbital administration upon bile salt metabolism and biliary lipid secretion.

Specifically, we will discuss the effects of phenobarbital on bile acid synthesis in: (a) animals with total bile fistula who, before administration of drug, had achieved maximal bile acid synthesis and in: $(b)$ animals with physiologically intact EHC who normally have a low rate of bile salt synthesis. We will then discuss the effects of phenobarbital upon total bile salt, phospholipid, and cholesterol secretion in animals with total bile fistula as well as those with intact EHC.

\section{METHODS}

\section{Experimental model}

A description of the primate model together with details of animal management $(1,9)$, mechanical and electronic design of the apparatus (10) have been published. Briefly, healthy Rhesus monkeys of both sexes were trained to sit in restraining chairs for a period of 2-3 wk before surgical implantation of biliary and duodenal fistulas. The resultant exteriorized EHC allowed bile to pass from the biliary $\mathrm{t}$-tube through an electronic stream-splitter which continuously sampled a given fraction of secreted bile. The remainder of the secreted bile was simultaneously returned to the duodenum. The animals were allowed 3-5 wk to recover from surgery and were then studied under steadystate conditions. ${ }^{2}$

Two extreme states of the EHC were studied: complete diversion of bile (total bile fistula) and "intact" EHC. In total interruption of the EHC by bile fistula no bile salt returned to the intestine, none was reabsorbed, and, therefore, none returned to the liver. Under steady-state conditions, bile acid synthesis was high-approximately $2 \mathrm{mmol} /$ $24 \mathrm{~h}$ per animal (1). On the other hand, if only $5 \%$ of the diverted bile was collected and $95 \%$ simultaneously returned to the duodenum, the EHC could be considered physiologically "intact." In fact it has been shown that bile flow and biliary lipid secretion rates, that is, the total output from the liver per $24 \mathrm{~h}$ of bile salt (1), phospholipid (11), and cholesterol (11) are not significantly altered by this small (5\%) interruption of the EHC. Thus, using the chronic monkey model the following parameters could be determined accurately: $(a)$ the total secretion per $24 \mathrm{~h}$ by the liver of bile salt, phospholipid, and cholesterol from the respective bile salt, phospholipid, and cholesterol concentration and volume of the bile sample collected over $24 \mathrm{~h}:(b)$ the amount of the bile salt (or other biliary constituent) returned to the duodenum per $24 \mathrm{~h}$ which equals the amount of bile salt secreted by the liver minus the amount of bile salt collected in the sample: (c) the amount of bile salt absorbed and returned to the liver via the portal vein per $24 \mathrm{~h}$ which equals the amount of bile salt entering the intestine minus the daily fecal bile salt loss, and: $(d)$ the amount of bile acid synthesized per $24 \mathrm{~h}$ in the steady state which equals the total loss of bile salt per diem (i.e., the amount of bile salt in the collected sample plus the fecal loss per $24 \mathrm{~h}$ ).

\footnotetext{
${ }^{2}$ Steady-state conditions occur in those animals maintaining constant body weight on a constant caloric intake and who exhibit steady daily bile flow and bile-salt secretion rates.
} 
Experimental design, sample collection, and expression of results. All studies were carried out during steady-state conditions with each animal acting as its own control. Animals consumed $120-180 \mathrm{~g}$ or $500-750 \mathrm{cal}$ of Purina Monkey Chow per day (Ralston Purina, St. Louis, Mo.), which contained $62 \%$ carbohydrate, $15 \%$ protein, $2.5 \%$ fiber, $9 \%$ water, and $4.8 \%$ ash. Total lipid content determined in our laboratory on repeated occasions from different lots varied from 5.5 to $6.2 \%$ (mean 5.6). These lipids were comprised mainly of triglycerides $(96 \%)$ and fatty acids (4\%). Total sterol content was less than $0.1 \%$ of total lipid. Thus, animals consumed between 6.7 to $10.0 \mathrm{~g}$ (mean $8.4 \mathrm{~g}$ ) or 6090 cal (mean 75) total lipid, virtually all as triglyceride and fatty acid and less than $10 \mathrm{mg}$ total sterols per day.

Three animals with chronic total bile fistula and three animals with an intact EHC were studied. Predrug control periods of sufficient time (usually 5-7 days) were carried out to insure steady daily bile flow and biliary bile-salt secretion rates. Bile samples were collected over a $24 \mathrm{~h}$ period and then stored at $-20^{\circ} \mathrm{C}$. Sodium phenobarbital, $5 \mathrm{mg} / \mathrm{kg}$ per day, was then administered via the duodenal fistula to each animal three times per day in equally divided doses. The drug was administered until at least 4 consecutive days of steady-state conditions were achieved. Between 2 and 3 days were needed to reach the new steady state. After cessation of phenobarbital the animals were allowed to reach a new steady state. Usually 2-3 days were needed to reach this postdrug control steady state but one animal took 7 days to return to precontrol values. To judge the consistency of drug response, one animal with an intact EHC was given phenobarbital on three separate occasions. Each steady-state drug period was separated by a steadystate control period. Thus four control and three drug periods were carried out.

In two animals with intact EHC, bile-salt synthetic rates and bile-salt pool size were determined during control periods and then repeated after the animal had reached a new steady state on drug treatment. Bile salt pool sizes were determined by the washout technique of Dowling, Mack, and Small (1). Biliary lipid composition was expressed as the relative molar concentrations of bile salt, phospholipid, and cholesterol according to the method of Admirand and Small (13). Feces were collected daily and stored at $-20^{\circ} \mathrm{C}$ in plastic bags. Later 2- to 3-day fecal pools were thawed, homogenized with 2 parts water, and a $30 \mathrm{~cm}^{3}$ portion sonicated (12) before bile acid analysis.

Laboratory procedures. Biliary bile salt was measured by the hydroxysteroid method of Talalay (14) as modified by Admirand and Small (13). Phospholipid was determined as inorganic phosphorous by the method of Bartlett (15). Cholesterol was measured by a modification of the method of Schoenheimer and Sperry (16). Bile $(0.5 \mathrm{ml})$ was added to $4.5 \mathrm{ml}$ of isopropyl alcohol, shaken vigorously for $60 \mathrm{~s}$, and the precipitated protein and pigment spun down by centrifugation at $1500 \mathrm{rpm}$ for $10 \mathrm{~min}$. The digitonin precipitate was washed with acetone to remove any remaining pigment when necessary.

Fecal bile acids were extracted by the method of Evrard and Janssen (17) and measured by the method of Sandberg, Sjoväll, Sjoväll, and Turner (18) with the following minor modifications. An initial extraction of the fecal portion with $0.5 \mathrm{~N} \mathrm{HCl}$ in absolute alcohol was carried out to insure adequate extraction of conjugated bile acids from feces as described by Manes and Schneider (19). The final extract in benzene was purified by using a silicic acid column according to the method of Eneroth, Hellström, and Sjoväll (20). Tracer doses of radioactive cholic, de- oxycholic, or lithocholic acid were used as internal standards and recoveries of $84.4-100 \%$ (mean $92 \%$ ) were accepted. TFA derivatives of bile-acid methyl esters were run on a Packard gas chromatogram, model 7401/562 with hydrogen flame ionization detector (Packard Instrument Co., Downers Grove, III). 4-ft columns packed with $1 \%$ QF-1 on Gas-chrom Q (Applied Science Labs, Inc., State College, $\mathrm{Pa}$.) were maintained at $230^{\circ} \mathrm{C}$ during bile acid determinations. Bile acids were quantitated by means of planimetry by comparing areas under peaks from unknown samples, to that of a known cholanic acid standard.

\section{Statistical analysis}

In each individual animal the differences between control and drug periods were analyzed by Student's $t$ test method (21). The overall data for all monkeys were analyzed by an analysis of variance for a $2 \times 2$ factorial arrangement of treatments. Since the number of observations (n) in the subgroups was not equal, an approximate method using unweighted means and the harmonic mean of the $n$ was used (see pages $385-386$, reference 21 ).

\section{RESULTS}

Bile salt synthesis and pool size

Animals with total bile fistula (100\% bile diversion). The effect of phenobarbital is illustrated in one animal in Fig. 1. In the predrug control period the synthetic rate (mean $\pm 1 \mathrm{SEM}$ ) was $1.95 \pm 0.16 \mathrm{mmol} / 24 \mathrm{~h}$. After days treatment the animal reached a new steady-state rate of $2.46 \pm 0.06 \mathrm{mmol} / 24 \mathrm{~h}$. 2 days after stopping the drug the synthetic rate returned to $1.91 \pm 0.07 \mathrm{mmol} / 24 \mathrm{~h}$ a value indistinguishable from the pre-drug control. The results for all three animals are given in Table I. Phenobarbital increased the level of bile acid synthesis in every

\section{$\mathrm{mmol} / 24 \mathrm{~h}$}

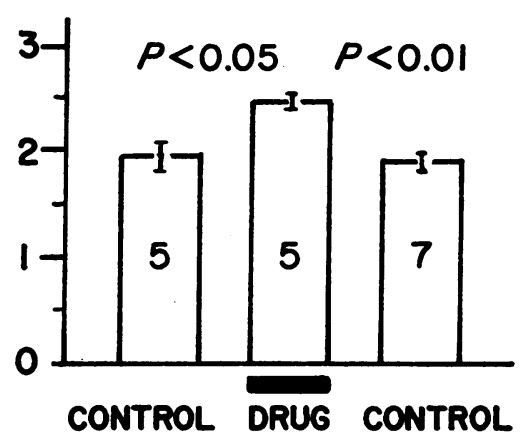

FIgURE 1 Bile acid synthesis before, during, and after phenobarbital treatment. The bars represent the mean synthetic rate $\pm I S E M$ of a 5 day steady-state predrug control period, a 5 day steady-state drug treatment period, and a 7 day steady-state postdrug control period. Numbers in bars refer to number of observations in each period. While on phenobarbital the synthetic rate was significantly greater than during either the predrug control period $(P<0.05)$ or postdrug control period $(P<0.01)$. The two control periods were not statistically different. 
TABLE I

Daily Bile Acid Synthesis in Animals with Total Bile Fistulas

\begin{tabular}{cccccc}
\hline Animal & Control & $\mathrm{n}$ & Phenobarbital & $\mathrm{n}$ & $P$ value \\
\hline & $m m o l / 24 h$ & & $m m o l / 24 h$ & & \\
$\mathrm{~A}$ & $1.66(0.13)$ & 5 & $2.28(0.06)$ & 7 & $<0.01$ \\
$\mathrm{~B}$ & $2.03(0.35)$ & 4 & $2.60(0.08)$ & 4 & $<0.001$ \\
$\mathrm{C}$ & $1.95(0.16)$ & 5 & $2.46(0.06)$ & 5 & $<0.05$ \\
\hline
\end{tabular}

During both control and phenobarbital periods, animals were in a steadystate condition and $\mathrm{n}$ refers to the total number of 24-h study periods for each experiment. The numbers in brackets refer to the SEM for each study. Thus, animals already having a maximal bile-acid synthetic rate during control periods increased their bile-acid synthetic rate significantly while on phenobarbital in each study.

animal with a total bile fistula $(P<0.05$ or better $)$, even though these animals were at maximal bile acid synthesis before drug treatment.

Animals with intact EHC (5\% bile diversion). In Table II the effects of phenobarbital on several aspects of bile salt metabolism in the three animals studied with an intact $\mathrm{EHC}$ ( $5 \%$ bile diversion) is given and the methods for measuring synthesis demonstrated. Columns 1 to 5 give in succession the amount of bile salt in the collected sample, returned to the duodenum, secreted, lost in feces, and absorbed and returned to the liver, respectively. Column 6 gives the percent of bile entering the intestine which is readsorbed in the steady state.
The percent readsorbed varied from animal to animal but all three animals absorbed somewhat more efficiently while on the drug. Bile acid synthesis was significantly enhanced by phenobarbital in all three animals (Table II, column 7). In animals B and D the pool size during the control period was 0.639 and $0.640 \mathrm{mmol}$ respectively. The pool was increased by phenobarbital to $0.720 \mathrm{mmol}$ in animal $\mathrm{B}$ and to $1.130 \mathrm{mmol}$ in animal $\mathrm{D}$.

Bile flow and biliary bile salt, phospholipid, and cholesterol secretion

Animals with total bile fistula (100\% bile diversion). The results for bile blow and biliary lipid secretion rates per $24 \mathrm{~h}$ carried out in three animals with bile fistula are given for each animal in Fig. 2. The height of the histograms represent the mean bile flow or secretion rates of control and drug treatment period and the vertical bar \pm 1 SEM. Phenobarbital treatment increased bile flow significantly $(P<0.002$ or better $)$ in each animal. Bile salt and phospholipid secretion rates were also increased by the drug in all studies $(P<0.05$ or better). On the other hand, cholesterol secretion rate was decreased in one animal (animal A) but unchanged in the other two.

Animals with intact EHC (5\% bile diversion). To assess the consistency of response to phenobarbital, one animal was treated on three separate occasions with the

TABLE II

Effect of Phenobarbital on Bile Salt Metabolism in Animals with Intact EHC

\begin{tabular}{|c|c|c|c|c|c|c|c|c|c|c|}
\hline & lumn... & n...m. & $1 \ddagger$ & 2 & $3=1+2$ & 4 & $5=2-4$ & $\begin{array}{c}6=100 \\
-\frac{4}{2}(100)\end{array}$ & \multicolumn{2}{|l|}{$7 \ddagger=1+4$} \\
\hline \multicolumn{2}{|r|}{ Animal } & $\begin{array}{l}\text { Steady-state } \\
\text { periods } \\
\text { (number of } \\
\text { 24-h study } \\
\text { periods) }\end{array}$ & $\begin{array}{l}\text { BS* in } \\
\text { sample } \\
5 \% \text { of } \\
\text { secretion }\end{array}$ & $\begin{array}{c}\text { BS* returned } \\
\text { to animal } \\
=95 \% \text { of } \\
\text { secretion }\end{array}$ & $\begin{array}{c}\mathrm{BS}^{*} \\
\text { secretion }\end{array}$ & $\begin{array}{l}\text { BS* loss } \\
\text { in feces }\end{array}$ & $\begin{array}{c}\text { BS* } \\
\text { absorbed } \\
\text { and returned } \\
\text { to liver }\end{array}$ & $\begin{array}{c}\% \text { Total } \\
\text { BS* } \\
\text { entering } \\
\text { intestine } \\
\text { absorbed }\end{array}$ & $\begin{array}{l}\text { Bile acid } \\
\text { synthesis }\end{array}$ & \\
\hline \multirow[b]{2}{*}{ A } & & & & & & $\mathrm{mmol} / 24 \mathrm{~h}$ & & & & \multirow[b]{2}{*}{$P<0.05$} \\
\hline & $\begin{array}{l}\text { Control } \\
\text { Drug }\end{array}$ & $\begin{array}{r}6 \\
11\end{array}$ & $\begin{array}{c}0.42 .3(0.022) \\
0.500(0.025)\end{array}$ & $\begin{array}{l}8.04 \\
9.55\end{array}$ & $\begin{array}{r}8.46 \\
10.03\end{array}$ & $\begin{array}{l}0.125 \S \\
0.125 \S\end{array}$ & $\begin{array}{l}7.91 \\
9.43\end{array}$ & $\begin{array}{l}98.4 \\
98.7\end{array}$ & $\begin{array}{l}0.548(0.022) \\
0.628(0.025)\end{array}$ & \\
\hline B & $\begin{array}{l}\text { Control } \\
\text { Drug }\end{array}$ & $\begin{array}{l}3 \\
5\end{array}$ & $\begin{array}{l}0.397(0.029) \\
0.616(0.033)\end{array}$ & $\begin{array}{r}7.55 \\
11.71\end{array}$ & $\begin{array}{r}7.95 \\
12.33\end{array}$ & $\begin{array}{l}0.115 \\
0.122\end{array}$ & $\begin{array}{r}7.40 \\
11.59\end{array}$ & $\begin{array}{l}98.5 \\
99.0\end{array}$ & $\begin{array}{l}0.512(0.029) \\
0.739(0.033)\end{array}$ & $P<0.01$ \\
\hline D & $\begin{array}{l}\text { Control } \\
\text { Drug }\end{array}$ & $\begin{array}{l}19 \\
18\end{array}$ & $\begin{array}{l}0.550(0.018) \\
0.710(0.017)\end{array}$ & $\begin{array}{l}10.45 \\
13.50\end{array}$ & $\begin{array}{l}11.00 \\
14.21\end{array}$ & $\begin{array}{l}0.130 \\
0.125\end{array}$ & $\begin{array}{l}10.32 \\
13.38\end{array}$ & $\begin{array}{l}98.8 \\
99.2\end{array}$ & $\begin{array}{l}0.680(0.018) \\
0.835(0.017)\end{array}$ & $P<0.001$ \\
\hline
\end{tabular}

In these experiments $5 \%$ of the total volume of bile secreted is collected for analysis and the rest (95\%) returned to the animal. Mean values for control vs. phenobarbital periods are shown. Column 1 is the quantity of bile salt in the collected sample. Column 2 is the quantity of bile salt returned to the duodenum. Column 3, the total daily bile salt secretion equals column 1 plus 2 . Column 5 is the amount of bile salt absorbed and returned to the liver via the portal vein $(\mathrm{mmol} / 24 \mathrm{~h})$ and is derived by subtracting daily fecal bile salt losses (column 4) from the amount of bile salt which entered the intestine (column 2). Column 6 is the percent readsorption of bile salt. Under steady-state conditions, bile acid synthesis equals total bile salt loss. Thus, daily bile acid synthesis, column 7 , is the sum of bile salt loss in the collected sample plus the fecal loss. Synthesis was significantly increased in each animal $(P<0.05$ or better) when on phenoharbital.

* BS, bile salt.

$\ddagger$ Mean \pm 1 SEM

\& Calculated mean fecal bile salts losses. These values were taken from the mean of the fecal loss in all other experiments. No difference was found between fecal excretion during control or phenobarbital periods. 
A

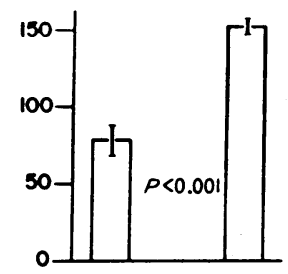

B

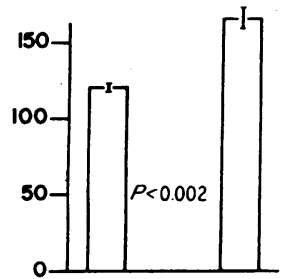

C

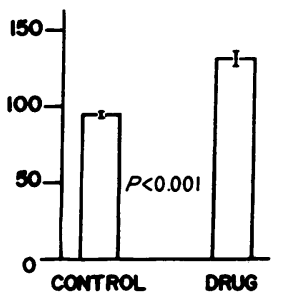

BLLE SALT

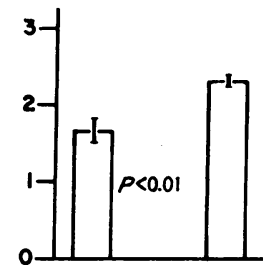

PHOSPHOLLD
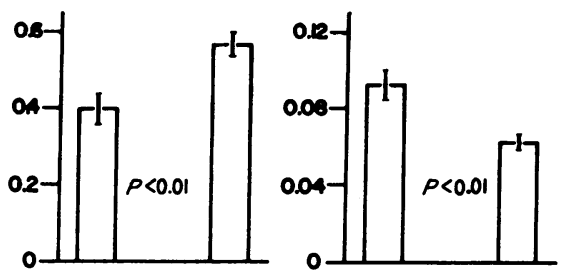

CHOLESTEROL
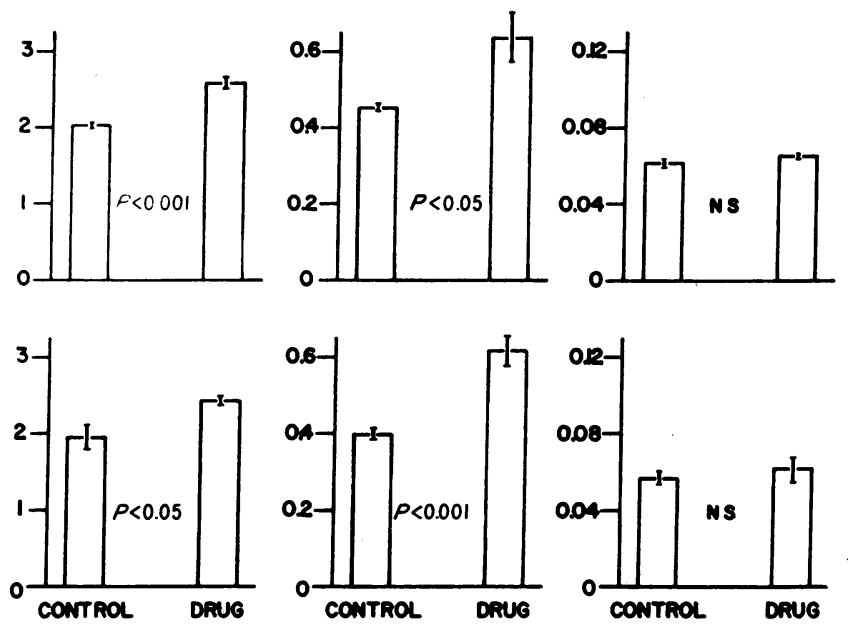

Figure 2 The effect of phenobarbital on bile flow and secretion rates of biliary lipids in the bile fistula animal. The histograms show from left to right, the means for bile flow and secretion rates of bile salt, phospholipid, and cholesterol in three monkeys studied with total bile fistula during control periods and drug treatment. The vertical bars represent \pm SEM. Note that bile salt secretion equals bile salt synthesis at $100 \%$ biliary diversion under steadystate conditions. Probability values, $P$, for each parameter have been determined by Student's $t$ test (21).

same dose of the drug ( $5 \mathrm{mg} / \mathrm{kg}$ per $24 \mathrm{~h}$ ). Each drug period was separated by a steady-state control period. In Fig. 3 the bile flow and bile-salt secretion rate for the four control periods and three drug treatment periods are shown. Except for the first predrug control period bile flow was always significantly lower in the control period compared with the drug treatment period. The bile-salt secretion rates behaved in a consistant manner. Each drug period showed a significantly higher secretion rate $(P<0.05$ or better) than either the control before or after. 2-3 days of nonsteady-state conditions separated each steady-state period. The results for bile flow and biliary lipid secretion for all three animals are summarized in Fig. 4. As in studies with complete biliary diversion, all animals with a physiologically intact EHC also experienced significantly increased bile flow when treated with phenobarbital $(P<0.001)$. Bile-salt secretion rates were also increased by phenobarbital treatment in all studies of animals with intact EHC
$(P<0.05$ or better $)$. Phospholipid secretion was also significantly increased in all animals $(P<0.01$ or better $)$ but cholesterol secretion was not significantly changed by drug treatment.

Relative concentrations of bile salt, phospholipid, and cholesterol in bile

Table III summarizes the results from animals with total bile fistula and intact EHC, showing the changes in bile composition resulting from phenobarbital administration. Whereas no consistent effects were noted in the relative proportions of bile salt or phospholipid in either $100 \%$ biliary diversion or "intact" EHC animals, a consistent decrease in the relative proportion of cholesterol in bile was found in every study. In three studies the decrease was significant $(P<0.05$ or better $)$ and in the other three studies the decrease was not significant. In addition, bile salt to cholesterol ratios were increased in every study. 

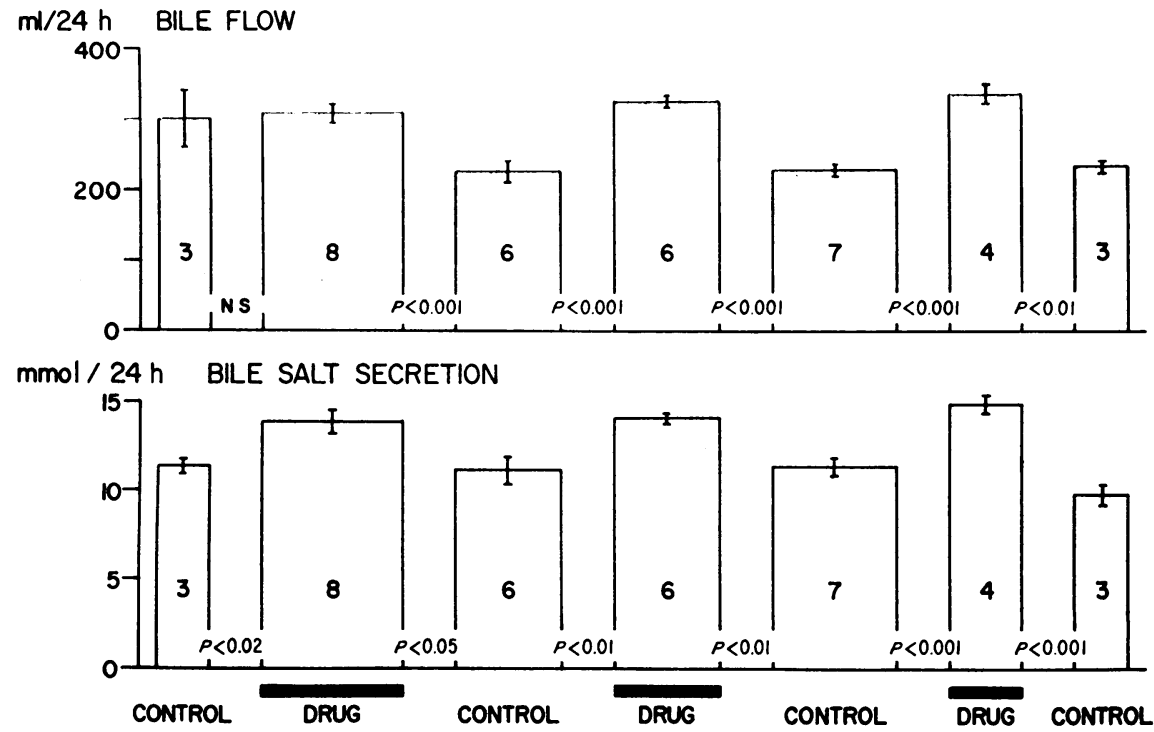

FIGURE 3 The effect of phenobarbital on bile flow and bile salt secretion rates in one animal with an intact EHC. The histograms and vertical bars represent mean \pm ISEM. The number within the histogram is the number of consecutive $24-\mathrm{h}$ steady-state periods. $P$ values between subsequent control and drug periods were determined by Students' $t$ test (21). 2-3 days of unsteady-state condition separate steady-state control and drug periods. Phenobarbital produces a consistent increase in bile flow and bile salt secretion.

Overall statistical analysis of bile flow, lipid secretion, and relative composition

Because of limitations in experimental technique the numbers of observations in the control and drug treatment subgroups were not the same. Thus the statistical analysis was handled in an unusual way (see methods). By analysis of variance of a $2 \times 2$ factorial arrangement of treatments we could draw the following conclusions (Table IV). First, in no case was there significant interaction. That is, any difference between intact EHC and bile fistula holds for controls as well as for drug treatment and any difference between controls and drug treatment holds for animals with total bile fistula as well as animals with an intact EHC. Second, in every case the difference between total bile fistula and an intact $\mathrm{EHC}$ is significant with a $P<0.001$. This conclusion was reached in earlier studies on other monkeys by different statistical techniques $(1,11)$. Third, phenobarbital significantly increased bile flow $(P<0.001)$, bile salt secretion $(P<0.01)$, and phospholipid secretion $(P<-0.05)$ above control values both in animals with bile fistulas and with intact EHC. In contrast, cholesterol secretion was not significantly altered. Finally phenobarbital significantly decreased the proportion of cholesterol in bile in both groups of animals $(P<0.001)$ but failed to significantly alter the proportion of bile salts or phospholipids.

\section{DISCUSSION}

Phenobarbital enhances bile flow in several species (2225 ). We have now found that bile flow is increased during steady-state conditions in the bile-diverted monkey as well as in the monkey with an intact EHC. The mechanism by which phenobarbital-induced hypercholeresis occurs has been a matter of speculation. It has been proposed that the osmotic effect produced by the active transport of bile acid anions out of the liver cell results in increased water and solute movement from the liver cell into the bile canaliculus (26). Thus, phenobarbital may increase bile flow by increasing bile salt secretion from the liver. Berthelot, Erlinger, Dhumeaux, and Preaux (27) have concluded from experiments in the rat, however, that the phenobarbital-induced increase in bile flow was due to the secretion of a bile-salt independent fraction of water in bile. On a plot of bile flow vs. bile-salt secretion rates, (Fig. 5) our control animals have a bile-salt independent fraction of approximately $70 \mathrm{~cm}^{3} / 24 \mathrm{~h}$ ( $y$ intercept at $\left.x=0\right)$, a value very similar to values $\left(71.7 \mathrm{~cm}^{3}\right)$ for other Rhesus monkeys studied earlier in this labortory (9). Phenobarbital-treated animals, however, secreted a bile-salt independent fraction of $102 \mathrm{~cm}^{3} / 24 \mathrm{~h}$. Therefore, there is an increase in the bile-salt independent fraction of bile flow in phenobarbital-treated animals. Since the slopes of the two lines were not significantly different, phenobarbital did not increase the amount of water secreted per mole of bile salt 
MONKEY FLOW $\mathrm{ml} / 24 \mathrm{~h}$

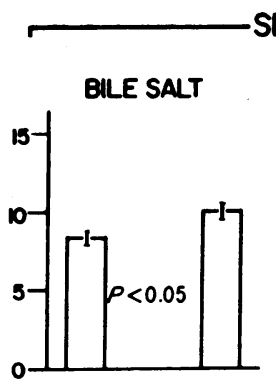

A

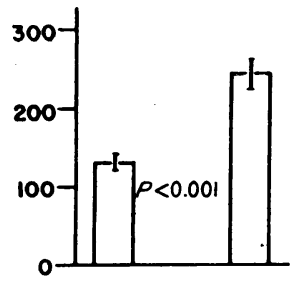

B

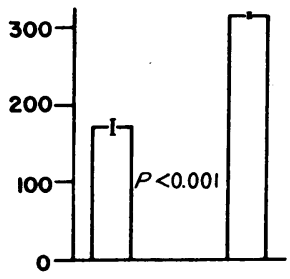

D

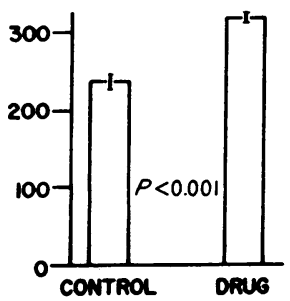

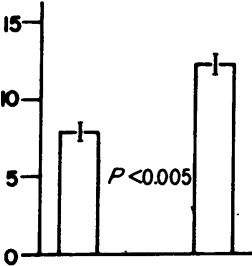

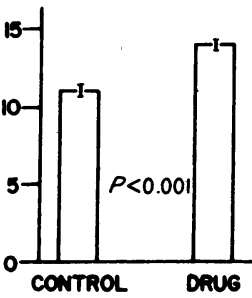

PHOSPHOLPD
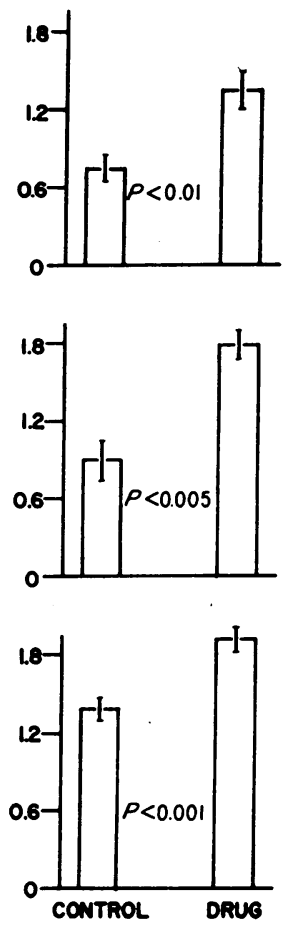

CHOLESTEROL
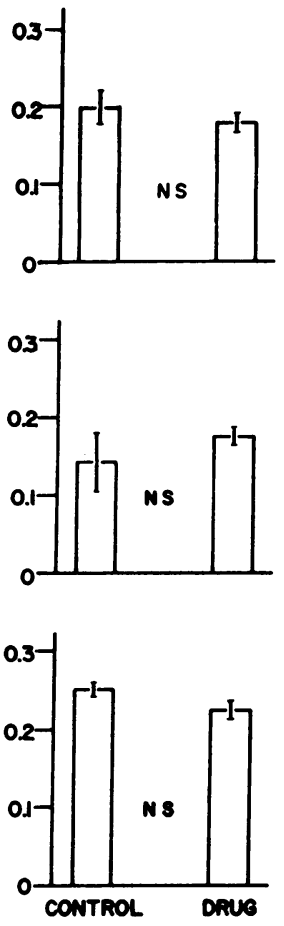

FIgURE 4 The effect of phenobarbital on bile flow and secretion rates of biliary lipids in animals with an intact EHC. The height of the histograms, represent the mean for control vs. phenobarbital periods in each animal for bile flow, and secretion rates of bile salt, phospholipid, and cholesterol. The vertical bar is IISEM. $P$ values were determined by Student's $t$ test (21). Increases in bile flow as well as bile salt and phospholipid secretion rates were found in all studies, while cholesterol secretion rate was unchanged.

secreted. However, we also found that phenobarbital increased total bile salt secretion over control values in all animals. We therefore conclude that the increased bile flow in phenobarbital-treated animals is the result of two processes: $(a)$ increased bile-salt independent flow and $(b)$ increased bile-salt secretion rates.

Since our experiments were carried out during steadystate conditions we avoided the problems associated with surgery (28), fasting (29), and interruption of the EHC, all of which have major effects on bile salt metabolism in the monkey. In addition to using a different species, we also employed a much smaller dose of phenobarbital than did Berthelot et al. (27) $(5 \mathrm{mg} /$ $\mathrm{kg}$ per day per animal vs. $100 \mathrm{mg} / \mathrm{kg}$ per day per animal). The dose we used, when compared with humans on a weight for weight basis, is close to that therapeutically employed for man (30). In fact, when we used doses as high as $30 \mathrm{mg} / \mathrm{kg}$ per day in two monkeys, these animals became ill and eventually experienced decreased bile formation. Thus, in monkeys under conditions of our experiments, phenobarbital in moderate doses increased both the bile-salt independent fraction of bile flow and the bile-salt secretion-dependent fraction.

Evidence for and against phenobarbital induction of $7 \alpha$-hydroxylation of cholesterol, the rate-limiting step in the conversion of cholesterol to bile salt, is present in the literature. Wada, Hirata, Nakao, and Sakamoto (31) have reported that $7 \alpha$-hydroxylation of cholesterol was greater in hepatic microsomal preparations from phenobarbital-treated Sprague-Dawley rats $(0.1 \%$ phenobarbital in diet) compared with control rats. Furthermore, this reaction was inhibited by carbon monoxide suggesting involvement of the electron transport system which functions in the induction of enzymes involved in the hydroxylation of many other drugs (32$36)$ and steroids $(37,38)$. Shefer, Hauser, and Mosbach (6) found that phenobarbital given intraperitonally (100 $\mathrm{mg} / \mathrm{kg}$ ) enhanced microsomal $7 \alpha$-hydroxylation of cholesterol sixfold in Wistar but not Sprague-Dawley rats. Furthermore Einarsson and Johansson (39) concluded from enzyme studies of Sprague-Dawley rat hepatic-microsomal preparations that neither $7 \alpha$-hydrox- 
TABLE III

Relative Composition and Bile Salt to Cholesterol Ratios in Animals with

Total Bile Fistula and with an Intact EHC

\begin{tabular}{|c|c|c|c|c|c|c|c|c|}
\hline \multirow[b]{2}{*}{ Animal } & \multirow{2}{*}{$\begin{array}{l}\text { Study } \\
\text { period } \\
\text { (n) }\end{array}$} & \multicolumn{6}{|c|}{ Relative composition (moles, \%) } & \multirow{2}{*}{ 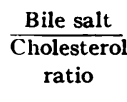 } \\
\hline & & Bile salt & & Phospholipid & & Cholesterol & & \\
\hline \multicolumn{9}{|l|}{ Total bile fistula } \\
\hline \multirow[t]{2}{*}{ A } & $\begin{array}{c}\text { Control } \\
\text { (5) }\end{array}$ & $75.85(1.94)$ & NS $\ddagger$ & $19.6(1.4)$ & NS & $4.63(0.53)$ & $P<0.001$ & 16.4 \\
\hline & $\begin{array}{l}\text { Drug } \\
\text { (7) }\end{array}$ & $78.64(0.70)$ & & $19.2(0.66)$ & & $2.03(0.18)$ & & 38.7 \\
\hline \multirow[t]{2}{*}{ B } & $\begin{array}{c}\text { Control } \\
\text { (4) }\end{array}$ & $79.69(0.59)$ & NS & $17.90(0.53)$ & NS & $2.40(0.10)$ & NS & 33.2 \\
\hline & $\begin{array}{l}\text { Drug } \\
\quad \text { (4) }\end{array}$ & $78.41(1.60)$ & & $19.26(1.34)$ & & $1.98(0.25)$ & & 39.8 \\
\hline \multirow[t]{2}{*}{$\mathrm{c}$} & $\begin{array}{c}\text { Control } \\
(5)\end{array}$ & $80.76(1.15)$ & NS & $16.79(0.89)$ & $P<0.05$ & $2.46(0.29)$ & NS & 32.8 \\
\hline & $\underset{\text { Drug }}{(5)}$ & $78.49(0.74)$ & & $19.58(0.63)$ & & $1.93(0.14)$ & & 40.7 \\
\hline \multicolumn{9}{|c|}{ Intact EHC $5 \%$ bile diversion } \\
\hline \multirow[t]{2}{*}{ A } & $\begin{array}{c}\text { Control } \\
\text { (6) }\end{array}$ & $89.70(1.13)$ & $P<0.05$ & $8.18(0.97)$ & $P<0.01$ & $2.12(0.23)$ & $P<0.05$ & 42.3 \\
\hline & $\begin{array}{l}\text { Drug } \\
\text { (11) }\end{array}$ & $86.60(0.67)$ & & $11.88(0.67)$ & & $1.56(0.09)$ & & 55.5 \\
\hline \multirow[t]{2}{*}{ B } & $\begin{array}{c}\text { Control } \\
\text { (3) }\end{array}$ & $88.35(1.28)$ & NS & $10.07(1.00)$ & NS & $1.57(0.29)$ & NS & 56.3 \\
\hline & $\begin{array}{l}\text { Drug } \\
\quad(5)\end{array}$ & $86.16(0.44)$ & & $12.56(0.72)$ & & $1.28(0.13)$ & & 67.3 \\
\hline \multirow[t]{2}{*}{$\mathrm{D}$} & $\begin{array}{l}\text { Control } \\
\text { (19) }\end{array}$ & $86.99(0.60)$ & NS & $10.96(0.57)$ & $\mathrm{NS}$ & $2.02(0.07)$ & $P<0.001$ & 43.1 \\
\hline & $\underset{(18)}{\text { Drug }}$ & $87.10(0.56)$ & & $11.52(0.57)$ & & $1.38(0.07)$ & & 63.1 \\
\hline
\end{tabular}

In all studies phenobarbital decreased the proportion of cholesterol in bile. Significant reduction was present in three of six studies. In four of six studies a slight decrease in the proportion of bile salts was seen. Five of six studies showed a slight increase in the proportion of phospholipid. The bile salt to cholesterol ratio was increased by the drug in each study.

* Mean \pm I SEM.

$\ddagger$ NS not significant by Student's $t$ test $(21)$.

ylation of cholesterol nor $12 \alpha$-hydroxylation of $7 \alpha$-hydroxylest-4-ene-3-one were enhanced in phenobarbitaltreated animals (dose $100 \mathrm{mg} / \mathrm{kg}$ intraperitoneally) compared with controls. They did find, however, that $7 \alpha$-hydroxylation of taurodeoxycholic acid was enhanced in phenobarbital-treated animals. Differences in animal species as well as route and total dosage of drug used may explain these apparent discrepancies in results.

Bile acid synthesis is maximal during steady-state 1 conditions in animals at $100 \%$ biliary diversion (1).
Phenobarbital, however, raised this level of "maximal bile acid synthesis" well above the normal range (Fig. 6 ) in all three monkeys suggesting that $7 \alpha$-hydroxylation of cholesterol was enhanced. Normally bile acid synthesis is significantly inhibited by feedback inhibition of bile salt returned to the liver via the portal vein in the intact animal (4). It is clear from the relation between bile acid synthesis rate and the rate at which bile salts return to the liver, as illustrated in control monkeys by the shaded zone in Fig. 6 , that above a criti-

TABLE IV

Statistical Analysis of All Experiments

\begin{tabular}{|c|c|c|c|c|c|c|c|}
\hline & \multicolumn{7}{|c|}{$P$ values } \\
\hline & \multirow[b]{2}{*}{ Flow } & \multicolumn{3}{|c|}{ Secretion rates } & \multicolumn{3}{|c|}{ mole \% } \\
\hline & & Bile salt & Phospholipid & Cholesterol & Bile salt & Phospholipid & Cholesterol \\
\hline Control vs. drug & $<0.001$ & $<0.01$ & $<0.05$ & NS & NS & NS & $<0.001$ \\
\hline $\begin{array}{l}\text { Intact EHC ( } 5 \% \text { diversion vs. } \\
\text { total bile fistula) }\end{array}$ & $<0.001$ & $<0.001$ & $<0.001$ & $<0.001$ & $<0.001$ & $<0.001$ & $<0.001$ \\
\hline Interaction & NS & NS & NS & NS & NS & NS & NS \\
\hline
\end{tabular}


cal rate of bile salt return (approximately $7 \mathrm{mmol} / 24$ h) bile acid synthesis normally becomes increasingly suppressed as the rate of return is increased. One would, therefore, expect bile acid synthesis to be largely suppressed or completely inhibited by increased bile salt secretion produced by phenobarbital in animals with physiologically intact EHC since more bile salt would be reabsorbed and returned to the liver. This, however, was not the case in phenobarbital-treated animals. When bile acid synthesis was plotted against bile salt returned to the liver (Fig. 6), our animals, during the control period, followed the normal relationship of return vs. synthesis. During drug treatment, however, in spite of increased rate of bile salt returned to the liver, bile acid synthesis was increased rather than decreased. Thus, phenobarbital partly overcomes the normal control of bile acid synthesis exerted by the hepatic return rate of bile salts. Furthermore, increased bile acid synthesis resulting from phenobarbital administration coupled with unaltered fecal loss resulted in an expanded bilesalt pool size in the two animals with intact EHC in which the pool was measured before and during drug treatment.

It is known that phenobarbital-induced proliferation of the smooth endoplasmic reticulum ${ }^{3}$ is characterized by an increase in both phospholipid and protein content, as well as enzyme induction (7). Young, Powell, and McMillan (8) have recently shown that hepatic microsomal preparations from male adult rats, pretreated with $70 \mathrm{mg} / \mathrm{kg}$ per day phenobarbital given intraperitoneally, exhibited significant increases in the specific activity of the enzyme governing phosphatidylcholine synthesis by sequential methylation of phosphatidylethanolamine. In addition, they also showed that in vivo incorporation of $\left[\right.$ methyl $\left.^{-3} \mathrm{H}\right]$ from $\mathrm{L}-\left[\right.$ methyl $\left.{ }^{-} \mathrm{H}\right]$ methionine into hepatic microsomal phosphatidylcholine was increased more than threefold over control animals while comparable increases in serum phospholipids were not seen. Thus, the enhanced phospholipid secretion into bile seen in all our experiments supports the above findings and suggests that phospholipid synthesis along with that of bile acid was enhanced by phenobarbital administration.

The secretion of the other major bile lipid, cholesterol, was not increased as a result of phenobarbital treatment in the monkey. Jones and Armstrong (40) as well as Wade, Hirata, and Sakamoto (41) have shown that hepatic microsomal preparations from rats pretreated with phenobarbital (dose $100 \mathrm{mg} / \mathrm{kg}$ intra-

${ }^{3}$ That phenobarbital did produce hypertrophy of the smooth endoplasmic reticulum at the doses we used was verified by liver biopsy and electron microscopic examination. (Courtesy of Dr. Jerry Trier, Department of Medicine.)

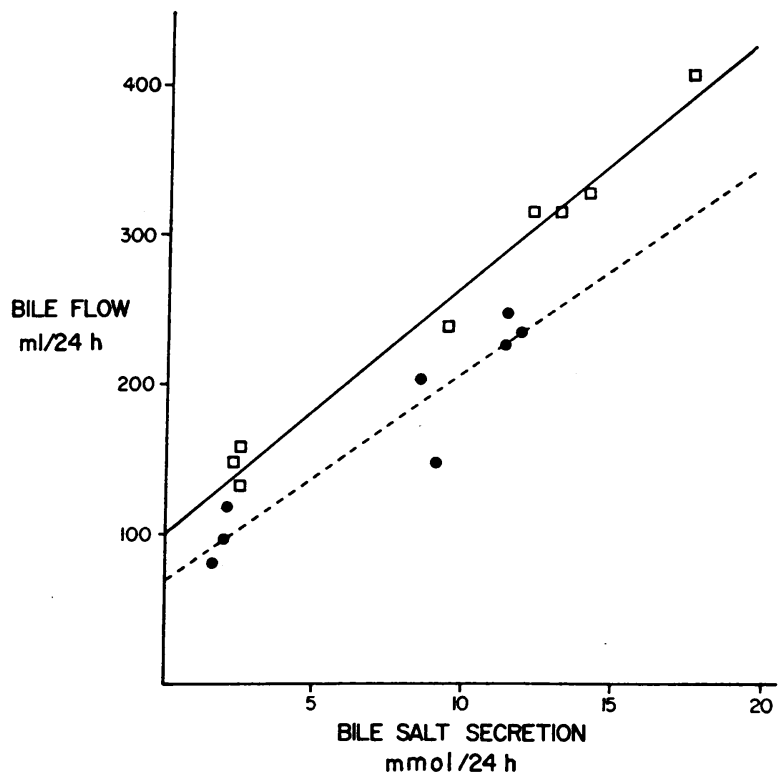

FIGURE 5 Relation between bile flow and bile salt secretion in control and phenobarbital-treated animals. Lines were drawn by method of least squares. Phenobarbital-treated animals, open squares, fall along line of equation $y=16.5 x$ +102 while control animals (closed circles) fall on lines $y=13.7 x+70$. This control relation is almost identical with relation found previously (9) for Rhesus monkeys of same weight, $y=12.8 x+71.7$. Increases in bile flow with increased bile salt secretion are evident in both control and phenobarbital-treated animals but the slope of lines are not significantly different. Phenobarbital, however, produced increased bile flow; $(a)$ by increasing the bile salt-independent fraction of bile flow from 70 to $102 \mathrm{ml}$ ( $y$ intercept of respective lines) and $(b)$ by increasing bile salt secretion.

peritoneally and $0.1 \%$ orally respectively) increase cholesterol synthesis from acetate or mevalonate, fourto fivefold. Since $80-90 \%$ of cholesterol degradation in the body occurs via metabolism of bile salts $(42,43)$ bile salt secretion might be enhanced without altering cholesterol secretion significantly even though cholesterol synthesis were concomittantly increased. In fact, Jones and Armstrong (40) found no increase in cholesterol accumulation in liver or plasma despite increased hepatic cholesterol synthesis which supports the contention that cholesterol and bile acid synthesis could both be stimulated by phenobarbital treatment but result solely in enhanced bile salt secretion in bile. In fact, the disparity between enhanced bile salt secretion and unaltered cholesterol secretion supports the hypothesis that phenobarbital enhances the conversion of hepatic cholesterol to bile salt. Similarly, the increased bile salt to cholesterol ratios in all studies are also consistent with this hypothesis. While bile salts have now been convincingly shown to inhibit cholesterol $7 \alpha$-hydroxylase activity $(3,4)$, the rate-limiting step in bile 


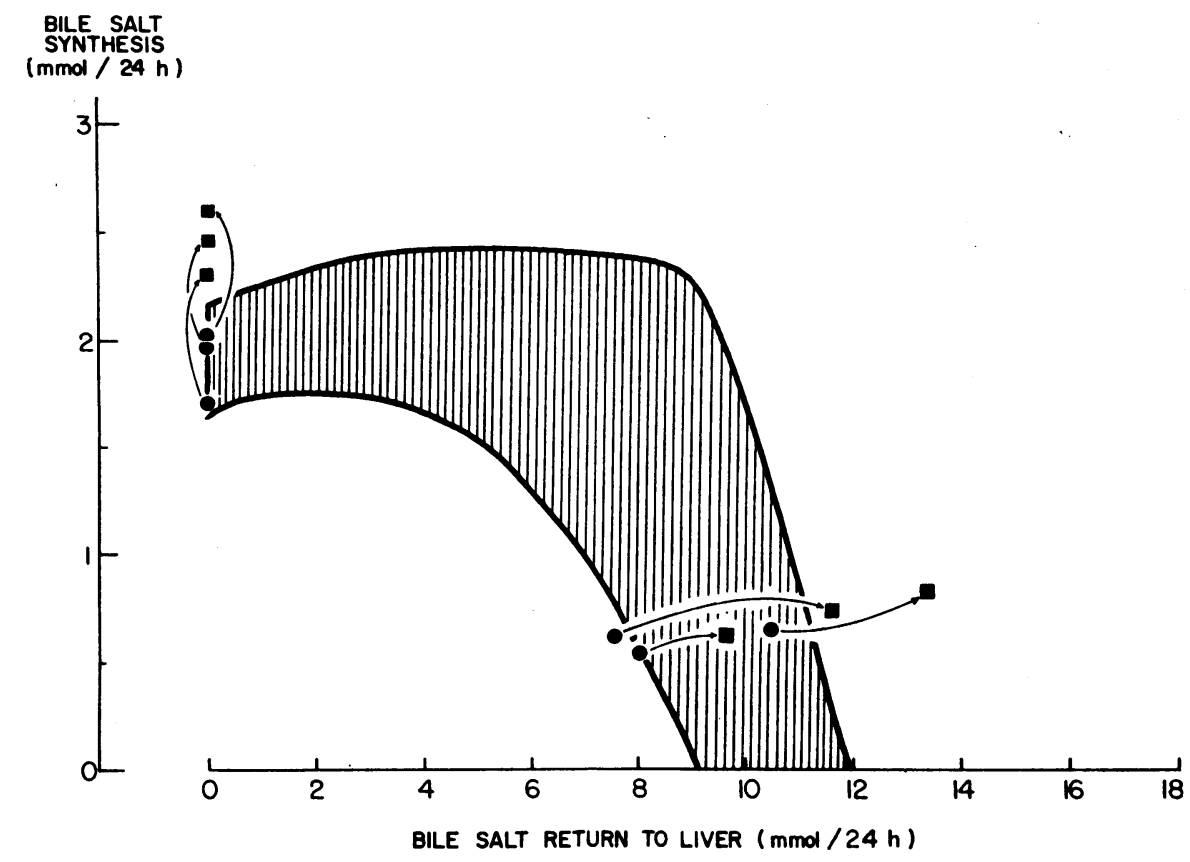

FIGURE 6 Relation between bile salt synthesis and bile salt returned to the liver. The shaded zone illustrates the relation between bile salt synthesis in mmol/24 $\mathrm{h}$ and rate of bile salt returned to the liver by the portal vein in mmol/24 h. The shaded area represents that zone covered by \pm 2 SEM for synthesis vs. return to the liver relations studied in 20 animals with varying interruptions of the EHC (1). Bile salt synthesis was not suppressed until rates greater than $7 \mathrm{mmol} / 24 \mathrm{~h}$ were returned to the liver. Total inhibition of bile salt synthesis required a return rate of about $12 \mathrm{mmol} / 24 \mathrm{~h}$. Monkeys during control periods (circles) fell within the normal zone but when treated with phenobarbital (squares) not only enhanced "maximal" bile salt synthesis when no bile salt was returned to the liver (left) but enhanced synthesis in spite of high return rates (right). (Individual points from columns 5 and 7 of Table II)

salt synthesis in the rat (3), our experiments in monkeys $(1,11)$ have shown that the rate of bile salt return to the liver controls the level of the bile acid synthesis. Other investigators (44) have concluded that bile salts exert feedback inhibition on 3-hydroxy-3methylglutamyl-CoA (HMG-CoA) reductase, the ratelimiting step in cholesterol synthesis. Phenobarbital has been shown to increase the activity of both hepatic enzymes $(6,41)$, and in our experiments to result in increased bile salt secretion. The increased return of bile salt to the liver could have theoretically resulted in inhibition of cholesterol synthesis. This appears unlikely from experiments carried out on various animal species subjected to acute biliary tract obstruction. In the rat, Weis and Dietschy (45), have shown that HMG-CoA reductase activity is increased along with cholesterol synthesis during acute biliary-tract obstruction. At the same time the amount of bile salt in the liver of the obstructed animals increased threefold (45). In experiments carried out on the Rhesus monkey we have found that bile salt synthesis was inhibited during acute biliary-tract obstruction probably as a result of bile salt retained within the liver during obstruction (46). Further, during the postobstructive period bile salt synthesis remains depressed but cholesterol secretion is markedly increased (46). Thus, it seems improbable that bile salts in the liver directly inhibit hepatic cholesterol synthesis.

Since both bile salt and phospholipid to cholesterol ratios were significantly increased by phenobarbital in all our studies, a very significant lowering of the relative concentration of cholesterol in bile was found in phenobarbital-treated animals. Thus, bile was formed which had a greater cholesterol-holding capacity. These results are noteworthy in that they may have significant therapeutic implications in the treatment or prevention of human cholelithiasis. By improving bile composition, the prevention of gallstones in high risk populations (47) may be possible. Further, the dissolution of "silent" gallstones may also be possible (48). We have consequently undertaken a clinical study to examine the effects of phenobarbital upon human hepatobiliary physi- 
ology and to determine whether a safe medical regimen of phenobarbital administration would be beneficial to patients with abnormal bile or cholesterol cholelithiasis.

\section{ACKNOWLEDGMENTS}

This work was supported by NIH Grant AM II453.

\section{REFERENCES}

1. Dowling, R. H., E. Mack, and D. M. Small. 1970. Effects of controlled interruption of the enterohepatic circulation of bile salts by biliary diversion and by ileal resection on bile salt secretion, synthesis, and pool size in the rhesus monkey. J. Clin. Invest. 49: 232.

2. Eriksson, S. 1957. Biliary excretion of bile acids and cholesterol in bile fistula rats. Bile acids and steroids. Proc. Soc. Exp. Biol. Med. 94: 578.

3. Shefer, S., S. Hauser, I. Bekersky, and E. H. Mosbach. 1970. Biochemical site of regulation of bile acid biosynthesis in the rat. J. Lipid Res. 11: 404.

4. Shefer, S., S. Hauser. I. Bekersky, and E. H. Mosbach. 1969. Feedback regulation of bile acid biosynthesis in the rat. J. Lipid Res. 10: 646.

5. Conney, A. H., and J. J. Burns. 1962. Factors influencing drug metabolism. Adv. Pharmacol. 1: 31.

6. Shefer, S., S. Hauser, and E. H. Mosbach. 1972. Stimulation of cholesterol $7 \alpha$-hydroxylase by phenobarbital in two strains of rats. J. Lipid Res. 13: 69.

7. Myasnikov, A. L. 1958. Influence of some factors on development of experimental cholesterol atherosclerosis. Circulation. 17: 99 .

8. Young, D. L., G. Powell, and W. O. McMillan. 1971. Phenobarbital-induced alterations in phosphatidylcholine and triglyceride synthesis in hepatic endoplasmic recticulum. J. Lipid Res. 12: 1.

9. Dowling, R. H., E. Mack, J. Picott, J. Berger, and D. M. Small. 1968. Experimental model for the study of the enterohepatic circulation of bile in rhesus monkeys. J. Lab. Clin. Med: $72: 169$.

10. Berger, J., R. Redinger, and D. M. Small. 1970. Instrument for sampling and measuring bile flow. Med. Biol. Eng. 8: 19.

11. Dowling, R. H., E. Mack, and D. M. Small. 1971. Biliary lipid secretion and bile composition after acute and chronic interruption of the enterohepatic circulation in the rhesus monkey. J. Clin. Invest. 50: 1917.

12. Bliss, C. M., D. M. Small, and R. M. Donaldson, Jr. 1971. The use of sonication to eliminate sampling and storage error in stool fat determinations. Clin. Res. 19: 387.

13. Admirand, W. H., and D. M. Small. 1968. The physicochemical basis of cholesterol gallstone formation in man. J. Clin. Invest. 47: 1043.

14. Talalay, P. 1960. Enzymatic analysis of steroid hormones. Methods Biochem. Anal. 8: 119.

15. Bartlett, G. R. 1959. Phosphorus assay in column chromatography. J. Biol. Chem. 234: 466.

16. Schoenheimer, R., and W. M. Sperry. 1934. A micromethod for the determination of free and combined cholesterol. J. Biol. Chem. 106: 745.

17. Evrard, E., and G. Janssen. 1968. Gas-liquid chromatographic determination of human fecal bile acids. $J$. Lipid Res. 9 : 226.

18. Sandberg, D. H., J. Sjoväll, K. Sjoväll, and D. A.
Turner. 1965. Measurement of human serum bile acids by gas-liquid chromatography. J. Lipid Res. 6: 182.

19. Manes, J. D., and D. L. Schneider. 1971. Extraction of bile acids from rat feces containing cholestyramine. J. Lipid Res. 12 : 376.

20. Eneroth, P., K. Hellström, and J. Sjoväll. 1968. A method for quantitative determination of bile acids in human feces. Bile acids and steroids. 195. Acta Chem. Scand. 22: 1729.

21. Snedecor, G. W., and W. G. Cochran. 1956. Statistical Methods Applied to Experiments in Agriculture and Biology. Iowa State University Press, Ames, Iowa. 5th edition.

22. Roberts, R. J., and G. L. Plaa. 1967. Effect of phenobarbital on the excretion of an exogenous bilirubin load. Biochem. Pharmacol. 16: 827.

23. Hart, L. G., A. M. Guarino, and R. H. Adamson. 1969. Effects of phenobarbital on biliary excretion of organic acids in mice and female rats. Am. J. Physiol. 217: 46.

24. Klaassen, G. D. 1969. Biliary flow after microsomal enzyme induction. J. Pharmacol. Exp. Ther. 168: 218.

25. Robinson, S. H. 1969. Increased bilirubin conjugation in heterozygous gunn rats treated with phenobarbital. Nature (Lond.). 222: 990.

26. Sperber, I. 1959. Secretion of organic anions in the formation of urine and bile. Pharmacol. Rev. 11: 109.

27. Berthelot, P., S. Erlinger, D. Dhumeaux, and A. M. Preaux. 1970. Mechanism of phenobarbital-induced hypercholeresis in the rat. Am. J. Physiol. 219: 809.

28. Redinger, R. N., A. H. Herman, and D. M. Small. 1971. Effects of surgery on hepatic physiology in the primate. Gastroenterology. 60: 975.

29. Redinger, R. N., A. H. Herman, and D. M. Small. 1971. Effect of diet on bile composition in the rhesus monkey. Gastroenterology. 60: 198. (Abstr.)

30. Goodman, L. S., and A. Gilman. 1970. Hypnotics and Sedatives. The Pharmacological Basis of Therapeutics. The Macmillan Company, New York, 4th edition. 98.

31. Wada, F., K. Hirata, K. Nakao, and Y. Sakamoto. 1968. Participation of P-450 in $7 \alpha$-hydroxylation of cholesterol. J. Biochem. (Tokyo). $64: 415$.

32. Orrenius, S., G. Dallner, and L. Ernster. 1964. Inhibition of the TPNH-linked lipid peroxidation of liver microsomes by drugs undergoing oxidative demethylation. Biochem. Biophys. Res. Commun. 14: 329.

33. Orrenius, S., and L. Ernster. 1964. Phenobarbital-induced synthesis of the oxidation demethylating enzymes of rat liver microsomes. Biochem. Biophys. Res. Commun. 16: 60 .

34. Orrenius, S. 1965. On the mechanism of drug hydroxylation in rat liver microsomes. J. Cell Biol. 26: 713.

35. Orrenius, S., J. I. E. Ericsson, and L. Ernster. 1965. Phenobarbital-induced synthesis of the microsomal drugmetabolizing enzyme system and its relationship to the proliferation of endoplasmic membranes. A morphological and biochemical study. J. Cell Biol. 25: 627.

36. Kato, R. 1966. Possible role of P-450 in the oxidation of drugs in liver microsomes. J. Biochem. (Tokyo). 59: 574.

37. Estabrook, R. W., D. Y. Cooper, and O. Rosenthal. 1963. The light-reversible carbon monoxide inhibition of the steroid C-21 hydroxylase system of the adrenal cortex. Biochem. Z. $338: 741$.

38. Omura, T., R. Sato, D. Y. Cooper, O. Rosenthal, and R. W. Estabrook. 1965. Function of cytochrome P-450 of microsomes. Fed. Proc. 24: 1181.

39. Einarsson, K., and G. Johansson. 1968. Effect of pheno- 
barbital on the conversion of cholesterol to taurocholic acid. Bile acids and steroids 204. Eur. J. Biochem. 6: 293.

40. Jones, A. L., and D. T. Armstrong. 1965. Increased cholesterol biosynthesis following phenobarbital induced hypertrophy of agranular endoplasmic reticulum in liver. Proc. Soc. Exp. Biol. Med. 119: 1136.

41. Wada, F., K. Hirata, and Y. Sakamoto. 1967. Relation of cholesterol synthesis and NADPH oxidation by microsomial electron transport system involving P-450. Biochim. Biophys. Acta. 143: 273.

42. Siperstein, M. D., and I. L. Chaikoff. 1952. C ${ }^{14}$-cholesterol. III. Excretion of carbons 4 and 26 in feces, urine, and bile. J. Biol. Chem. 198: 93.

43. Siperstein, M. D., M. E. Jayko, I. L. Chaikoff, and W. G. Dauben. 1952. Nature of the metabolic products of $\mathrm{C}^{14}$-cholesterol excreted in bile and feces. Proc. Soc. Exp. Biol. Med. 81 : 720 .
44. Back, P., B. Hamprecht, and F. Lynen. 1969. Regulation of cholesterol biosynthesis in rat liver: diurnal changes of activity and influence of bile acids. Arch. Biochem. Biophys. 133: 11.

45. Weis, H. J., and J. M. Dietschy. 1969. Failure of bile acids to control hepatic cholesterogenesis: evidence for endogenous cholesterol feedback. J. Clin. Invest. 48: 2398.

46. Redinger, R. N., S. M. Strasberg, and D. M. Small. 1971. Effects of acute biliary tract obstruction on bile salt and cholesterol metabolism. Clin. Res. 19: 401.

47. Sampliner, R. E., P. H. Bennett, L. J. Commess, F. A. Rose, and T. A. Burch. 1970. Gallbladder disease in pima indians. Demonstration of high prevalence and early onset by cholecystography. N. Engl. J. Med. 283 : 1358.

48. Small, D. M. 1970. The formation of gallstones. Adv. Intern. Med. 16: 243. 